\title{
Gerbil Fibroma
}

National Cancer Institute

\section{Source}

National Cancer Institute. Gerbil Fibroma. NCI Thesaurus. Code C134561.

Fibroma that occurs in a gerbil. 